\title{
O ATIVISMO POPULAR E O PAPEL DAS MÍDIAS DIGITAIS: REFLEXOS DE UM NOVO MODELO DE EXERCER DEMOCRACIA NO CENÁRIO CONTEMPORÂNEO E SEUS IMPACTOS NA ESFERA POLÍTICA
}

\author{
THE POPULAR ACTIVISM AND THE ROLE OF DIGITAL MEDIA: REFLECTIONS OF \\ A NEW MODEL TO EXERCISE DEMOCRACY IN CONTEMPORARY SCENE AND ITS \\ IMPACTS ON THE POLITICAL SPHERE
}

Andy Portella Battezini

Advogada, especialista em Direito Tributário e Gestão de Pessoas pela Universidade Anhanguera - Uniderp. Mestranda em Direito Democracia e Sustentabilidade pela Faculdade Meridional. Menbro do grupo de pesquisa Direito, Novas Tecnologias e Desenvolvimento. E-mail: andy_battezini@hotmail.com

Karla Cristine Reginato Advogada, Pós-graduanda em Direito Previdenciário pela Rede de Ensino Luiz Flávio Gomes-Anhanguera Uniderp. Mestranda em Direito pela Faculdade Meridional. karlacreginato@hotmail.com.

Recebido em: 14/06/2016

Aprovado em: 24/08/2016

Doi: $10.5585 / \mathrm{rdb} . v 15 i 6.401$

RESUMO: O presente estudo pretende demonstrar a apropriação de condutas ativistas em especial por parte dos usuários de internet e redes sociais, sob a perspectiva das novas ferramentas de tecnologia da informação e sua tendência globalizante. Tais ferramentas foram capazes de potencializar, ainda mais, as mobilizações populares em todo o território nacional. Nesse contexto, busca-se apresentar a viabilidade em adotar as mídias digitais como instrumento basilar de articulação e suporte, apto a dar visibilidade para questões de cunho político-social que necessitem condutas ativistas. Objetiva-se, então, compreender as transformações da sociedade atual com o advento das novas tecnologias de comunicação. Para isso, em um primeiro momento, será trabalhada a definição e os desdobramentos do termo ativismo, destacando o posicionamento de alguns autores sobre sua aplicação na prática. No tópico seguinte, será abordada a influência dos canais de comunicação na participação ativa dos cidadãos em atos coletivos, o poder dessas mídias no cotidiano, bem como, a contribuição de importantes filósofos da atualidade como Castells, Lévy e Lemos. No último tópico, esse estudo demonstrará a forma de atuação dos movimentos sociais em rede, na consecução do pedido de impeachment da atual presidente da república. Por fim, para realização deste ensaio foram utilizados o método indutivo e a técnica de categoria de conceitos operacionais. Já como instrumento procedimental foi realizada a investigação bibliográfica de textos doutrinários, meios eletrônicos e coleções particulares.

Palavras chaves: Ativismo; Mídias Digitais; Sociedade de Informação.

ABSTRACT: This study aims to demonstrate the ownership of pipelines activists from the perspective of new information technology tools and its globalizing trend, able to enhance even more the popular mobilizations throughout the country. In this context, we seek to show the 
feasibility of adopting the digital media as a basic instrument of coordination and support, able to give visibility to the issues of political and social nature involving activists conduct. if the objective is then to understand the transformations of contemporary society with the advent of new communication technologies. For this, it will be working at first with the definition and consequences of activism term, highlighting the positioning of some authors about their application in practice. The next topic will address the influence of communication channels in the active participation of citizens in collective actions, as well as the contribution of important current philosophers such as Castells, Lévy and we read about the power of communication media in everyday of people. And finally, will be demonstrating the form of action of social movements in the network in achieving the impeachment due to the current president of the republic. For this test we used the inductive method, the category of technical operational concepts, such as procedural instrument the bibliographical research doctrinal texts, electronic media, and private collections.

Keywords: Activism; Digital Media; Information Society.

SUMÁRIO: Introdução; 1. Os desdobramentos do termo ativismo e sua aplicação prática; 2. A influência das mídias digitais no ativismo social; 3. Das redes para as ruas - O processo de ativismo social-político no ato de Impeachmant Presidencial; Considerações finais; Referências.

\section{INTRODUÇÃO}

A presença das tecnologias de informação e comunicação tem representado um papel fundamental no contexto democrático contemporâneo. É possível perceber isso, diante das expressivas atuações da população brasileira manifestando, tanto nas ruas quanto nas mídias sociais, o seu descontentamento com os problemas político-sociais vivenciados nas últimas décadas. Essa nova onda de manifestações garantiu destaque, inclusive, na mídia internacional. $\mathrm{O}$ jornal americano The New York Times reportou a forte influência das redes sociais no Brasil e no mundo, evidenciando o canal de relacionamento facebook como principal aliado dos ativistas. Isso porque, foi através desse canal que os ativistas puderam ordenar os detalhes da passeata e os pontos a serem reivindicados para, assim, propalar o número de adeptos nas participações.

Nesse sentido, o presente trabalho tem como objetivos compreender as transformações da sociedade atual com o advento das novas tecnologias de comunicação (internet e redes sociais) e sua tendência exponencial; evidenciar os instrumentos midiáticos de propagação e mobilização de condutas ativistas; conceituar e diferenciar o ativismo popular de ativismo judicial; contrastar o papel das mídias digitais como forma de organização e articulação de movimentos sociais; e relatar um dos principais movimentos políticos já exercidos por intermédio das esferas de comunicação tecnológica.

O problema de pesquisa consubstancia-se na tentativa de endossar uma definição operacional ao conceito de ativismo e, também, na necessidade de compreender as objeções atribuídas aos movimentos políticos na rede. Desse modo, justifica-se estudar o envolvimento das mídias digitais com o propósito ativista, a fim de compreender esse novo modelo de articulação política, o qual deixa evidente a renovação da imagem dos movimentos de protesto, cada vez mais presentes no cenário pátrio.

Para realização deste ensaio foi utilizado o método indutivo, a técnica de categoria de conceitos operacionais e, como instrumento procedimental, a investigação bibliográfica de textos doutrinários, meios eletrônicos e coleções particulares.

Para isso, será trabalhada, em um primeiro momento, a definição e os desdobramentos do termo ativismo, destacando o posicionamento de alguns autores a respeito de sua aplicação na 
prática. No tópico seguinte, será abordada a influência dos canais de comunicação na participação ativa dos cidadãos em atos coletivos e o poder dessas mídias de comunicação no cotidiano. Esse mesmo tópico também irá mostrar a contribuição de importantes filósofos da atualidade, como Castells, Lévy e Lemos, sobre a referida temática. E, para finalizar, o estudo demonstrará como atuaram os movimentos sociais nessas mídias, na execução do pedido de impeachment da atual presidente da república.

O tema é tão importante e amplo, que será enfocado apenas alguns pontos favoráveis, levando em consideração o atual cenário de mobilizações político-sociais. Assim, o presente artigo tem por finalidade refletir como as mídias digitais tem um papel significativo no processo de tomada de decisões, e na construção de uma democracia pautada na participação popular.

\section{OS DESDOBRAMENTOS DO TERMO ATIVISMO E SUA APLICAÇÃO PRÁTICA}

Nos dias de hoje, é comum deparar-se com os equívocos traçados tanto pela doutrina quanto pelos magistrados acerca do verdadeiro significado de ativismo. Todavia, apesar do seu vocábulo não ser uníssono, considerando a pluralidade de denominações, para a ciência Jurídica importa na atuação demasiada do poder judiciário em detrimento das lacunas ou omissões deixadas no âmbito dos poderes executivo e legislativo.

Antes de adentrar no mérito da questão do que realmente se configura o ativismo judicial, inicialmente, cumpre esclarecer qual o verdadeiro significado isolado do termo ativismo. Segundo o dicionário Aurélio, a acepção ativista refere-se a "militante político". Já por ativismo, Assis (2006) incumbe "(...) qualquer ação positiva (fazer algo) que tenha implicações concretas, e geralmente imediatas, sobre seus alvos".

$\mathrm{Ou}$, ainda, conforme entendimento de Jordan:

Ativismo é essencialmente algo feito conjuntamente por muitas pessoas, mas deve-se ter cuidado com o senso de grupo ou de coletivo que se é empregado aqui. (...) Deve existir um sentimento de identidade compartilhada, a qual pode ser melhor compreendida pelo reconhecimento da raiva, medo, esperança e outras emoções sentidas no processo de transgressão social. Solidariedade e transgressão, coletividade e ação, são os gêmeos do ativismo. O que separa o ativismo de multidões saindo do cinema, ou grupos reunidos, é que os ativistas reconhecem uns nos outros o desejo de transformar a maneira pela qual suas vidas são vividas (JORDAN, 2002, p. 12).

Desse modo, percebe-se que o ativismo é resultante dos anseios de um grupo de pessoas, com a mesma ideologia ou convicção, que desejam alterar as reais condições impostas tanto pela esfera pública quanto privada. Tal prática implica em participações ativas da coletividade, visando revolucionar e alterar determinadas realidades sociais.

Por isso, é possível detectar na sociedade contemporânea diferentes tipos de ativismo. Destacam-se como os mais comuns o ativismo popular ou social, podendo ser encontrado na literatura sua divisão em subclasses (cultural, político, ambiental e cibernético), e o ativismo judicial, o qual é motivo de muitas críticas no cenário atual, principalmente por parte dos adeptos á corrente jurídico-hermenêutica.

$\mathrm{O}$ ativismo judicial diferencia-se, e muito, do ativismo decorrente das mobilizações sociais, pois nele é possível verificar um rompimento da postura positivista em detrimento da atuação proativa dos juízes no processo de criação da norma jurídica (NEGRELY, 2010). Nesta seara, para melhor compreensão, destaca-se o entendimento de Elival da Silva Ramos sobre a definição do que se restringe o ativismo judicial: 
[...] exercício da função jurisdicional para além dos limites impostos pelo próprio ordenamento que incumbe, institucionalmente, ao Poder Judiciário fazer atuar, resolvendo litígios de feições subjetivas (conflitos de interesse) e controvérsias jurídicas de natureza objetiva (conflitos normativos). Há como visto, uma sinalização claramente negativa no tocante às práticas ativistas, por importarem na desnaturação da atividade típica do Poder Judiciário, em detrimento dos demais Poderes. Não se pode deixar de registrar mais uma vez, o qual tanto pode ter o produto da legiferação irregularmente invalidado por decisão ativista (em sede de controle de constitucionalidade), quanto o seu espaço de conformação normativa invadido por decisões excessivamente criativas (RAMOS, 2010, p. 129).

Dessa forma, entende-se por ativismo judicial o fato de o judiciário ir além da sua atuação diante dos poderes que lhe são outorgados pela ordem jurídica. Essa acepção, que vem sendo empregada com maior frequência no cenário brasileiro, é motivo de muitas críticas. O jurista Lenio Streck aborda em mais de uma de suas obras (Verdade e Consenso; O que é istodecido conforme minha consciência?) a recepção equivocada e insatisfatória adotada pelos tribunais em alguns julgados ao fazer uso do ativismo judicial.

Conforme entendimento de Streck (2011), o ativismo configura-se como um desvio na atuação do judiciário, ou seja, "um juiz ou tribunal pratica ativismo quando decide a partir de argumentos de política, de moral, enfim, quando o direito é substituído pelas convicções pessoais de cada magistrado (ou de um conjunto de magistrados)".

Essa mesma crítica também é abordada por Dworkin ao referir que:

O ativismo é uma forma virulenta de pragmatismo jurídico. Um juiz ativista ignoraria o texto da Constituição, a história de sua promulgação, as decisões anteriores da Suprema Corte que buscaram interpretá-la e as duradouras tradições de nossa cultura política. O ativista ignoraria tudo isso para impor a outros poderes do Estado seu próprio ponto de vista sobre o que a justiça exige. $\mathrm{O}$ direito como integridade condena o ativismo e qualquer prática de jurisdição constitucional que lhe esteja próxima (DWORKIN, 1999, p. 451-452).

Percebe-se que tanto Streck quanto Dworkin adotam posições contrárias ao ativismo judicial, fundamentando que os juízes ou magistrados estariam a confrontar com os demais poderes da república, excedendo do seu poder de interpretação da norma por meio de decisões subjetivas e, até mesmo, inconstitucionais.

Contudo, a doutrina favorável, a exemplo de Luis Roberto Barroso e André Ramos Tavares, incumbe a aplicação do ativismo judicial considerando a realidade histórica de cada Estado. Tavares (2008) contribui afirmando que há uma "necessidade em desmistificar os poderes totalmente independentes, quanto mais numa distribuição tripartite". Ademais, a tese da absoluta separação entre os poderes os tornaria perniciosos e arbitrários".

Já Barroso (2011) imprime o ativismo judicial como uma postura valorativa de fins constitucionais do Poder Judiciário que possibilita uma interferência mais ampla na atuação dos demais poderes. Percebe-se, assim, que a ideia de ativismo judicial prolatada por parte da doutrina sintetiza a legitimidade do Poder Judiciário para invalidar as decisões decorrentes do executivo e do legislativo. Dessa maneira, o judiciário estaria apenas fazendo uso das atribuições conferidas pela próprio Texto Constitucional, já que é dever do juiz atuar conforme preconiza a lei e não em causa própria (GRANJA, 2013).

Em meio a este cenário, denota-se que o ativismo judicial é fonte de muitas divergências e repercussões tanto pela doutrina quanto pelos tribunais. Esse descompasso advém de uma crise vivenciada desde a promulgação da Carta, em 1988, deixando lacunas até então não sanadas pela atual Constituição Brasileira, e assim, contribuindo para um sistema cada vez mais arbitrário. 
Por outro lado, diferente do ativismo judicial, que remete á conduta dos magistrados sobre a apreciação do texto jurídico, o ativismo social, ou também denominado popular, evidencia uma abrangência mais ampla nas mais variadas dimensões (políticas, sociais, culturais, ambientais e sentimentais) em relação aos processos de manifestação popular, conforme será demonstrado.

Não há como negar que nos dias atuais há uma grande presença de grupos nas ruas, no congresso e nas redes sociais proclamando por melhorias ou reivindicando a efetivação de seus direitos. Isso tudo por causa do regime democrático adotado pelo Texto Constitucional de 1988. A sociedade demonstra cada vez mais interesse em questões que envolvem o poder público, a igualdade de direitos e a proteção aos interesses difusos.

Essa busca em reivindicar por práticas suscetíveis de transformar a realidade social defendendo um ideal comum pode ser chamada de ativismo social. Ativismo, pois, é necessário condutas proativas em relação a uma identidade-causa. Assis (2006) descreve o perfil ativista como "O ativista é um agente engajado, movido por sua ideologia a práticas concretas - de força física ou criativa - que visam desafiar mentalidades e práticas do sistema sócio-políticoeconômico, construindo uma revolução a passos pequenos", ou ainda "O 'ativista' também mobilizaria um sentido político mais relevante do que o vocábulo 'militante" (ASSIS, 2006).

Paralelamente Postmes e Brunsting (2002) estabelecem que o ativismo consiste "em ações tomadas por indivíduos ou grupos para um propósito coletivo, como a defesa de uma ideia ou ideologia particular, ou a luta política com outro grupo". Desse modo, verifica-se que o ativista social é aquele indivíduo ou grupo que se engaja em prol de alguma causa. Pode-se ter o ativista ambiental que atua na área pública ou não governamental em questões envolvendo o espaço ecológico. O ativista político que clama, principalmente, por mudanças condizentes a administração do poder público. Ou ainda o ativista cibernético que busca mobilizar as pessoas por meio dos processos de comunicação eletrônicos, mais especificamente pelo uso da internet, em face de valores e interesses diversos.

Todavia, apesar de alguns estudiosos estabelecerem como espécie o perfil ativista cibernético ou em rede (ZAGO; BATISTA, 2012), verifica-se certa dificuldade em enquadrá-lo como subclasse do ativismo. Isso se deve ao fato de que o ativismo cibernético pode ser condição para executar as demais espécies de ativismo, com exceção do judicial.

Entretanto, insta salientar que as redes telemáticas como mecanismo para concretizar o ativismo são, sem dúvidas, o melhor ambiente para disseminar e fomentar a participação da coletividade. Nesse sentido, pretende-se demonstrar mais detalhadamente no tópico a seguir a influência das mídias digitais como meio de propagação para concretização do ativismo social.

\section{A INFLUÊNCIA DAS MÍDIAS DIGITAIS NO ATIVISMO SOCIAL}

A sociedade contemporânea vivencia um novo momento, as mudanças estão acontecendo e implicam em reaver os modelos tradicionais de participação popular consolidados no regime constitucional democrático de 1988. Isso significa que a democracia está mais presente do que antes Um dos fatores que vêm contribuindo significativamente para isso é o uso das mídias tecnológicas em favor da sociedade.

Há quem discorde com a disseminação dos meios tecnológicos, mais especificamente com o acesso á internet e redes sociais, alegando que eles contribuem para uma geração de jovens e adultos não-pensantes, influenciados por canais de informação de fontes duvidosas, ou ainda, que eles utilizem essas ferramentas com o intuito de lesar ou prejudicar a conduta de um indivíduo ou de uma coletividade.

De fato, não há como negar a intenção ardilosa manifestada por muitos através dos meios de comunicação. Todavia, percebe-se que a tecnologia veio muito mais para somar do que impor desordem no cotidiano das pessoas. Por isso a importância em estudar e demonstrar as 
dimensões da atual sociedade em rede, principalmente, diante dos interesses homogêneos em detrimento do descontentamento com as três esferas do poder, qual seja, o executivo, legislativo e o judiciário.

Um indivíduo, sozinho, é incapaz de proclamar pela efetividade de seus direitos. Para isso, é necessária uma organização conjunta, capaz de mobilizar grupos com os mesmos interesses envolvidos e, assim, desenvolver alianças de alcance global, hábeis de formular estratégias com base em suas concepções identidárias. Esse recente conceito, quando realizado pela internet, representa um novo paradigma social que pode ser denominado como ativismo digital, midiático, em rede ou ainda ciberativismo, conforme consta em estudos acadêmicos.

$\mathrm{O}$ ativismo realizado pelos canais de comunicação tecnológicos diferencia-se dos demais pelo seu alcance, pois utiliza as ferramentas cibernéticas para promover ações que visam o mesmo objetivo. Além disso, a tendência é expandir a um curto lapso de tempo informações e estratégias não apenas em âmbito regional, mas também em âmbito global. Dessa maneira, é possível, através do uso da internet, militar por causas que estejam ocorrendo do outro lado do planeta, ou também por causas que já vem acontecendo com frequência: os excessos praticados pelo poder público.

Batista define esse novo momento:

[...]como toda a estratégia que visa a uma transgressão social - uma transformação na agenda pública - pela difusão de conteúdos por meio da ampliação exponencial das capacidades comunicativas dos atores sociais na Internet. $\mathrm{O}$ novo panorama em relação aos engajamentos políticos contemporâneos, em razão das facilidades comunicativas proporcionadas pelo meio, indica a politização do meio e das práticas coletivas na rede (BATISTA, 2012, p. 72).

Nesse contexto, presencia-se uma sociedade em evolução, ou uma sociedade de informação, com um novo modelo de desenvolvimento sócio-político na busca pela satisfação das necessidades dos cidadãos e pela disseminação de conhecimento. Garcia Marques e Lourenço Martins denominam bem esse novo momento:

A sociedade de informação - expressão que cada vez importa menos definir na medida em que vai se vivendo em maior escala - assenta sobre o uso óptimo das novas tecnologias de informação e de comunicação, em respeito pelos princípios democráticos, da igualdade, da solidariedade, visando o reforço da economia e da prestação de serviços públicos, e, afinal, a melhoria da qualidade de vida de todos os cidadãos (MARQUES; MARTINS, 2000, p. 43).

Através da sociedade em rede percebe-se um aumento na participação dos cidadãos, principalmente, nas questões que envolvem interesses político-sociais. Tanto que o próprio Estado passou a executar práticas de transparência ao fazer uso dos mecanismos digitais, possibilitando, assim, que os cidadãos acompanhem mais de perto os atos praticados pela administração pública. Tudo isso só é possível devido á evolução proporcionada por essa nova era de conhecimento.

Desse modo, denota-se que o ativismo está intimamente conectado a essa nova sociedade de informação, representando uma evolução no papel democrático-constitucional e também na própria liberdade de expressão, já que não depende de instituições mediadoras. $\mathrm{O}$ importante é que a sociedade se mobilize por causas relevantes, o que já está acontecendo por causa da ampliação exponencial dos setores de comunicação e dos atores sociais por meio da internet. 
Da mesma forma, esse poder das ferramentas midiáticas é observado por importantes filósofos da atualidade como Castells (2005), Levy (1999) e Lemos (2002). Na acepção de Castells, vislumbra-se um momento histórico, caracterizado por grupos interconectados que recebem, produzem e transmitem informações aos demais. Essa circulação de dados e notícias, fruto da internet, é denominada pelo autor de "sociedade em rede". Ainda sob a mesma perspectiva assevera Castells:

O valor agregado da internet sobre outros meios de comunicação é sua capacidade de recombinar, no tempo escolhido, produtos de informação e processos de informação para gerar um novo resultado, que é imediatamente processado na Net, em um interminável processo de produção de informação, comunicação e resposta em tempo real ou livremente determinado. Isso é crucial porque a recombinação é a fonte da inovação, e a inovação está na raiz da produtividade econômica, criatividade cultural e produção de poder político (CASTELLS, 2004, p. 11).

Por outro lado, Levy, importante estudioso no campo das mídias cibernéticas e culturais, busca traçar suas percepções acerca da evolução do ciberespaço. O autor ainda enfatiza as capacidades cognitivas humanas, como o saber imaginário, criativo e racional imerso na própria cultura tecnológica. Nesse mesmo sentido, Levy (1999) acrescenta que as relações no espaço virtual "são construídas sobre afinidades de interesses, de conhecimentos, sobre projetos, em um processo mútuo de cooperação e troca".

Tais reflexões apontadas por Levy deixam claro o papel histórico e centralizador das mídias para se tornar um incentivo de inteligência coletiva. $O$ autor ainda defende a inteligência coletiva não apenas delimitando a exposição do conteúdo, mas também na capacidade de reconhecer a inteligência do outro. Em outras palavras, os indivíduos envolvidos em um mesmo processo não podem discriminar alguém levando em consideração sua classe social, raça ou credo, uma vez que admitem seus conhecimentos e saberes individuais como resultado de sua formação. Assim, caso compartilhado, o conhecimento humano proporcionará diversos benefícios nas diferentes áreas humanas, valorizando a si e ao outro para juntos promoverem o crescimento do todo (LEVY, 2004).

Já Lemos (2005) caracteriza isso como "era conexão" e da "mobilidade". Os ensinamentos do autor partem do pressuposto que há cada vez mais uma relação intrínseca entre os espaços físicos da cidade e o espaço virtual das redes telemáticas. Para ele:

As práticas mundiais de utilização de telefones celular como SMS, o acesso a banco de dados, agindo como um controle remoto do quotidiano, tanto para fins políticos como hedonistas mostram o potencial de inclusão digital e de participação social na cibercultura (LEMOS, 2005).

E ainda:

A era da conexão parece estar colocando em sinergia espaço virtual, espaço urbano e mobilidade. Depois de séculos de esvaziamento do debate político no espaço público, esse fenômeno mostra o desgaste das atividades políticas clássicas e a emergência de novas formas micro-políticas de ação. As $m o b s^{l}$, por serem reuniões de pessoas em torno de uma performance sem caráter político,

\footnotetext{
${ }^{1}$ Lemos, André. Cibercultura e mobilidade. A era da conexão. Intercom - Sociedade Brasileira de Estudos Interdisciplinares da Comunicação XXVIII Congresso Brasileiro de Ciências da Comunicação - Uerj - 5 a 9 de setembro de 2005. Disponível em: http://www.intercom.org.br/papers/nacionais/2005/resumos/r1465-1.pdf. Acesso em: 30 jan. 2016.
} 
ou com caráter político explícito, revelam, por assim dizer, sua mais radical dimensão social. Ativismo global, hedonismo, micro política e nonsense, marcas da pós-modernidade, são aí evidentes. O vitalismo social em torno das mobsmostram essa vontade de conexão para além de uma vida política institucionalizada (LEMOS, 2005).

Nesse viés, verifica-se um novo paradigma, desenvolvido pelos meios digitais (internet), que redefine um novo conceito de ações orientadas pelos movimentos sociais em torno de protestos e manifestações por todo o mundo. Á medida em que os meios de comunicação evoluíram, novas perspectivas em torno da população foram se consolidando. Prova disso é o ativismo que quando realizado pela internet é capaz de potencializar, ainda mais, ações coletivas coordenadas com a mesma ambição.

Tão importante quanto militar em favor de posturas ativistas é saber projetá-las de forma consciente e integra. Desse modo não se atinge deslealmente a honra de um indivíduo, ou uma classe, e nem se faz uso de métodos que imponham violência no desempenho de suas ações. Ser ativista é cooperar e se solidarizar por mudanças de modo "a gerar reputação para promover a difusão de informações ao conceder visibilidade à rede de cooperação na perspectiva de atrair potenciais participantes através do respaldo coletivo" como bem atribui Batista e Zago (2009).

Diante do potencial midiático para a concretização do ativismo, que foi explanado até então, pretende-se, no próximo tópico, abordar um exemplo prático e recente de ativismo político: o caso do impeachment da Presidente da República (Dilma Rousseff), ocorrido nos meses de março e abril de 2015 e 2016, o qual teve repercussão mundial, devido a sua força e apoio por grande parte da população brasileira.

\section{DAS REDES PARA AS RUAS - O PROCESSO DE ATIVISMO SOCIAL-POLÍTICO NO ATO DE IMPEACHMANT PRESIDENCIAL}

Com o uso criativo das tecnologias de informação e comunicação, o contato de indivíduos, que até então se encontravam isolados geograficamente, acabou por facilitar, ainda mais, a aproximação em prol de códigos culturais, valores e interesses diversos. Diante da capacidade de organização e resistência por parte dos articuladores midiáticos, tornou-se inevitável restringir direitos relacionados á liberdade de expressão e pensamento em um Estado Democrático de Direito, como é o do Brasil, que se depara cada vez mais com a formação de novos movimentos sociais e novas formas de ativismo.

As formas de organização proporcionadas pelas redes de informação e relacionamento são, possivelmente, um dos principais alicerces para integrar, articular e expandir a participação de grupos identidários em prol da mesma causa. O potencial desse tipo de ação, quando realizado pelas ferramentas da web, permite ações coordenadas e a proliferação em todo território. Exemplo disso é o que aconteceu em 15 de março, 12 abril de 2015, e ainda, em 13 de março de 2016, esta última considerada a maior manifestação da história do país de acordo com indicativos jornalísticos ${ }^{2}$, quando grande parte da população brasileira reuniu-se, por meio de comunidades sociais, e foi para as ruas com o intuito de aclamar pela cassação do mandato da atual Presidente da República, Dilma Rousseff, exercitando assim, o que pode ser chamado de ativismo político.

\footnotetext{
2 http://politica.estadao.com.br/noticias/geral,manifestacoes-em-todos-os-estados-superam-as-de-marco-do-anopassado, 10000021047

http://brasil.elpais.com/brasil/2016/03/13/politica/1457906776 440577.html

http://www.bloomberg.com/news/articles/2016-03-13/brazil-protesters-assemble-as-rousseff-s-future-hangs-in-

$\underline{\text { balance }}$

http://www.wsj.com/articles/protesters-in-brazil-take-aim-at-governing-party-1457884257
}

Revista de Direito Brasileira | São Paulo, SP | v. 15 | n. 6 | p. 173 - 184 | set./dez. 2016 
$\mathrm{O}$ centro da questão pode ser resumido, basicamente, em dois aspectos. O primeiro seria o descontentamento, por parte da população brasileira, com as denúncias de corrupção envolvendo a empresa estatal Petrobrás. Já o segundo aspecto seria uma série de medidas tomadas para conter gastos pelos chamados reajustes fiscais, como aconteceu em diversos setores da administração pública, incidindo no aumento demasiado de impostos, a exemplo da tarifa de energia elétrica.

Nesse caso específico, há que observar que boa parcela da população recorreu as manifestações para impor um sentimento autoritário de indignação e revolta diante da real situação presenciada. Isso ocorreu, principalmente, após o período eleitoral, já que as promessas feitas pela Presidente, na campanha política do ano de 2014, consubstanciaram-se em um descontentamento social-político, logo após a Presidente se reeleger.

Em contrapartida, as pessoas utilizaram-se da prática do ativismo para militar por causas de interesses homogêneos, qual seja, a perda do poder político, com a consequente retirada do atual partido da presidência da república. Esses movimentos conquistaram destaque através das articulações promovidas nas mídias sociais, em especial pelo site de relacionamentos facebook. Tais articulações tinham o intuito de difundir e mobilizar o país a ir paras as ruas e protestar pela saída do atual governo e pode ser considerada, portanto, de acordo com levantamento da imprensa, a maior mobilização popular no país desde o início da Nova República ${ }^{34}$.

A propagação do movimento foi tão intensa que cidades como Buenos Aires, Nova York, Londres, Lisboa, Montreal e Miami também executaram o ativismo por meio de protestos nas ruas, organizados anteriormente por comunidades virtuais, ganhando assim, destaque na mídia internacional. O jornal americano The New York Times destacou a influência das redes sociais no ativismo político ocorrido em 15 de março no Brasil e ainda alegou que a força das mídias sociais está na democracia e na liberdade de expressão ${ }^{5}$. O ativismo cibernético gerou situações constrangedoras para muitos políticos, como lembrou esse mesmo jornal. Na Turquia, o primeiro-ministro, Recep Tayyip Erdogan, definiu as redes sociais como uma "ameaça para a sociedade". Conforme lembrou o The New York Times, o Parlamento da Turquia aprovou uma lei aumentando a capacidade do governo para censurar conteúdos online e expandir a vigilância. Erdogan ainda disse que consideraria bloquear o acesso aos sites facebook e YouTube . $^{6}$

Sob a lógica das novas tecnologias, há que destacar que está sendo modelado um novo fenômeno social-democrático no contexto pátrio. Um sentimento arraigado por esforços coletivos, por meio dos discursos midiáticos, revela a renovação da imagem através dos movimentos sociais. Ao valer-se dos mecanismos de comunicação, em conjunto com as práticas ativistas, articulações como a do impeachment demonstram que os cidadãos estão encorajados a lutar e provocar por mudanças nos mais diversos setores das estruturas contemporâneas. Dessa maneira, torna-se difícil para os governantes manter a legitimidade e o controle da esfera pública.

Assim, acredita-se que o ativismo exercido por meio das redes de comunicação contribui para o fortalecimento das demandas sociais, transformando os espaços, até então virtuais, em espaços físicos de mobilização. Diante disso, é impossível não associar as práticas de ativismo com a dimensão tecnológica e comunicativa. Dessa forma, cabe ao cidadão acompanhar as demandas sociais na luta por seus direitos e aproveitar os benefícios proporcionados pelas ferramentas digitais, contribuindo, então, para um país cada vez mais democrático, e instruído dos acontecimentos que sucedem na esfera pública.

\footnotetext{
${ }^{3}$ Marcos Coronato e Marco Vergotti (15 de março de 2015). Manifestação anti-Dilma entra para a história Época. Visitado em 01 de fevereiro de 2016.

${ }^{4}$ Paulista reúne maior ato político desde as Diretas-Já, diz Datafolha Folha de S.Paulo (15 de março de 2015). Visitado em 01 de fevereiro de 2016.

${ }^{5}$ Simon Romero (15 de março de 2015). In Nationwide Protests, Angry Brazilians Call for Ouster of President New York Times. Visitado em 02 de fev de 2015. Disponível em: http://www.nytimes.com/2015/03/16/world/angerbubbles-up-against-brazilian-president.html?ref=world\&_r=1.

${ }^{6}$ Disponível em: http://www.folhapolitica.org/2014/03/influencia-das-redes-sociais-no.html.
} 


\section{CONSIDERAÇÕES FINAIS}

Atualmente, se verifica, constantemente, manifestações promovidas pelos mais diversos grupos sociais em prol de um mesmo objetivo específico. A democracia é a alma do direito á liberdade de expressão, permitindo, assim, que os cidadãos difundam seus ideais de pensamento. Esse modelo de articulação social, em favor de interesses identidários, recebe a denominação de ativismo, o que significa dizer, no seu sentido político, trabalho desenvolvido especialmente por métodos revolucionários, ou, também, uma forma de militância.

Todavia, não há como comparar o ativismo exercido por meio dos movimentos comunitários com o ativismo realizado na esfera judicial. $O$ ativismo judicial em nada se assemelha aos métodos tradicionais praticados pelos militantes, pois ele decorre dos excessos cometidos pelos magistrados ao não se limitarem apenas ao que está adstrito na lei. Dessa forma, eles ultrapassam o poder que lhes é outorgado, para além do está disposto na Constituição.

Em contrapartida, o ativismo social, ou também popular (como é conferido por boa parte das revisões acadêmicas), apresenta-se como um sinônimo de luta social de extensão universal, pois não ocorre apenas no Brasil, mas sim perante os demais Estados consagrados sob o regime Democráticos de Direito. E, se vislumbrado pelos novos canais de comunicação eletrônica, é capaz de mobilizar e potencializar, ainda mais, atuações conjuntas, em um curto espaço de tempo, abrindo caminhos para um horizonte de experiências, culturas e valores compartilhados.

Os ativistas adeptos a essa nova realidade tecnológica migram de seus computadores para as ruas na busca por soluções concretas. A internet surge como um importante canal de disseminação do ativismo popular, tanto que, atualmente, é comum se deparar com movimentos desencadeados pelas redes de comunicação online, a partir de insatisfações por parte da população. Tais insatisfações são ocasionadas, principalmente, pela má administração dos agentes estatais. Nesse sentido, buscou-se destacar o movimento realizado em face do pedido de impeachment presidencial, ocorrido nos meses de março e abril de 2015, como a maior mobilização arquitetada no Brasil desde as Diretas-Já. A dimensão do protesto em todo país ganhou força através das marchas promovidas pelas redes sociais, com publicações e articulações diárias contra o governo, com o objetivo de confrontar a ordem estatal e proclamar por um governo leal a população.

Desse modo, apesar do ceticismo, por parte de algumas pessoas, em relação ao poder de instigação conferido pelos mecanismos digitais percebe-se que a população, se conectada, é capaz de promover mudanças significativas nas estruturas do poder. Isso porque, novos espaços de discussão, conhecimento e capacidade de empreender são criados, bem como técnicas, como a dos canais de veiculação online, transformam-se em instrumentos de poder na construção de laços sociais, o que é característico da atual sociedade de informação.

Assim, constata-se que o perfil do ativista, quando impulsionado pela apropriação das novas tecnologias, é fundamental para a potencialização dos novos espaços de articulação social. No entanto, cabe ao cidadão dar o primeiro passo para reivindicar, acompanhar e apontar o percurso que deve ser dado para as ações políticas, incorporando as redes digitais na consecução de seus ideais em prol de uma sociedade cada vez mais democrática e participativa.

\section{REFERÊNCIAS}

ALVES, Fernando Antonio. O ativismo popular nas redes sociais pela internet e o marco constitucional da multidão, no estado Democrático de direito: uma discussão prévia sobre participação popular e liberdade de expressão no Brasil, pós-manifestações de junho de 2013. REDESG / Revista Direitos Emergentes na Sociedade Global - www.ufsm.br/redesg v. 3, n. 1, jan.jun/2014. 
ASSIS. Érico Gonçalves de. Táticas lúdico-midiáticas no ativismo político contemporâneo. Dissertação de mestrado. São Leopoldo, Universidade do Vale do Rio dos Sinos (Unisinos), 2006.

BARROSO, Luís Roberto. Judialização, ativismo judicial e legitimidade democrática. In: COUTINHO, Jacinto, N. de Miranda; FRAGALE FILHO, Roberto; LOBÃO, Ronaldo (Orgs.). Constituição \& Ativismo judicial: limites e possibilidades da norma constitucional e da decisão judicial. Rio de Janeiro: Lumen Juris, 2011, p. 275 a 290.

BATISTA, Jandré Correa. Apropriações ativistas em redes sociais: cartografia das ações coletivas no twitter. Dissertação de mestrado, Porto Alegre, Pontifícia Universidade Católica do Rio Grande do Sul (PUC), 2012.

CASTELLS, Manuel. A Sociedade em Rede. vol.1 Trad. Roneide Venancio Majer com a colaboração de Klauss Brandini Gerhardt. 8 ed. São Paulo: Paz e Terra, 2005.

DWORKIN, Ronald. O império do direito. São Paulo: Martins Fontes, 1999.

GERVASONI; LEAL. Tássia Aparecida e Monica Clarissa Henning. Judialização da política e ativismo judicial na perspectiva do Supremo Tribunal Federal. Curitiba: Multideia, 2013.

GRANJA, Cícero Alexandre. O ativismo judicial no Brasil como mecanismo para concretizar direitos fundamentais sociais. In: Âmbito Jurídico, Rio Grande, XVI, n. 119, dez 2013. Disponível em: < http://www.ambitojuridico.com.br/site/?n_link=revista_artigos_leitura\&artigo_id=14052

>. Acesso em 26 de jan. 2016.

JORDAN, TIM. Activism! Direct action, hactivism and the future of society. Londres: Reaktion Books, 2002.

LEMOS, André. Cibercultura, tecnologia e vida social na cultura contemporânea. Porto Alegre: Sulina, 2002.

. Cibercultura e mobilidade. A era da conexão. Intercom - Sociedade Brasileira de Estudos Interdisciplinares da Comunicação XXVIII Congresso Brasileiro de Ciências da Comunicação Uerj - 5 a 9 de setembro de 2005. Disponível em: http://www.intercom.org.br/papers/nacionais/2005/resumos/r1465-1.pdf. Acesso em: 30 jan. 2016.

LÉVY, Pierre. Cibercultura. São Paulo: Ed. 34, 1999.

. Inteligencia Colectiva: por uma antroplogia del ciberespacio. Bibioteca Virtual em Salud, BIREME - OPS - OMS. Washington, 2004.

MARQUES, Garcia; MARTINS, Lourenço. Direito da informática. Coimbra: Almedina, 2000.

MACHADO, Jorge Alberto S. Ativismo em rede e conexões identitárias: novas perspectivas para os movimentos sociais. Sociologias, Porto Alegre, ano 9, nº 18, jul./dez. 2007. 
MACHADO, Jorge. Internet, Ativismo Político e Controles Governamentais, paper apresentado no XI Congresso da Sociedade Brasileira de Sociologia, Campinas, Brasil, 1 a 5 de setembro de 2003.

O Ciberespaço como Arquitetura da Liberdade - Tentativas de Territorialização e Controle da Rede. In ALVES, G.; MARTINEZ, V. (Orgs.) Dialética do Ciberespaço, Bauru: Práxis. Disponível em: <http://www.forum-global.de/bm/articles/ ciberespaco_territorializacao_jorgemachado.htm>. Acesso em: 02 fev. 2016.

NEGRELLY, Leonardo. O ATIVISMO JUDICIAL E SEUS LIMITES FRENTE AO

ESTADO DEMOCRÁTICO. Anais do do XIX Encontro Nacional do CONPEDI realizado em Fortaleza - CE nos dias 09, 10, 11 e 12 de Junho de 2010.

PAESANI, Liliana Minardi (coord.) O direito na sociedade da informação. São Paulo: Atlas, 2007.

POSTMES, Tom; BRUNSTING, Suzanne. Collective Action in the Age of Internet: Mass Communication and On-line Mobilization. In Social Science Computer Review, Vol. 20 No. 3. Estados Unidos: Sage Publications, 2002.

RAMOS, Elival da Silva. Ativismo judicial: parâmetros dogmáticos. São Paulo: Saraiva, 2010.

RECUERO, Raquel. As redes sociais na Internet. Porto Alegre: Sulina, 2009.

SILVEIRA, Sérgio A.; BRAGA, Sérgio; PENTEADO, Cláudio. Cultura político e ativismo nas redes digitais. São Paulo: Editora Fundação Perseu Abramo, 2014.

STRECK, Lenio Luiz. O que é isto - decido conforme minha consciência?.Volume 1. 4 ed. Porto Alegre: Livraria do Advogado, 2013.

STRECK, Lenio Luiz. Verdade e Consenso. 5 ed. São Paulo: Saraiva, 2011.

TASSINARI, Clarissa. Jurisdição e ativismo judicial. Limites da atuação do judiciário. Porto Alegre: Livraria do Advogado, 2013.

TAVARES, André Ramos. Curso de Direito Constitucional. 6 ed. ver. e atual. São Paulo: Saraiva, 2008.

ZAGO e BATISTA. Gabriela da Silva e Jandré Correa. Ativismo em redes sociais digitais: formas de participação em ações coletivas no ciberespaço. Verso e Reverso, v. 23, n.52, Unisinos, São Leopoldo, 2009.

_. Manifestações coletivas no ciberespaço: cooperação, capital social e redes sociais: In: II Simpósio nacional da ABCIBER, São Paulo, 2008.

Disponível em: http://folhapolitica.jusbrasil.com.br/noticias/114679334/influencia-das-redessociais-no-ativismo-politico-e-destaque-no-new-york-times. Acesso em: 2 fev. 2016. 